\title{
Strength Enhancement of Weak Subgrade Soil Using No Fines Concrete Nail
}

\section{An Experimental Study}

\author{
Ranjitha $\mathbf{J}^{1}$ \\ ${ }^{1}$ Assistant Professor, Department of civil engineering \\ Dayananda sagar college of engineering \\ Bengaluru, Karnataka \\ Kunal Kumar ${ }^{2}$, Farzana Mohamad ${ }^{3}$ \\ ${ }^{2,3}$ UG Student, Department of civil engineering \\ Dayananda sagar college of engineering \\ Bengaluru, Karnataka
}

\author{
Aishwarya I $S^{4}$ \\ ${ }^{4}$ UG Student, Department of civil engineering \\ Dayananda sagar college of engineering \\ Bengaluru, Karnataka \\ Keyur Shah ${ }^{5}$ \\ ${ }^{5}$ UG Student, Department of civil engineering \\ Dayananda sagar college of engineering \\ Bengaluru, Karnataka
}

\begin{abstract}
Road network plays a major role in contributing to the overall socio-economic, industrial, cultural development of the country. There arises requirement for special attention on the structural condition and function of the road structure. Structural adequacy of pavement depends on the subgrade which supports the above layers, withstanding the traffic loads and weather effects. Weak subgrade requires thick layers whereas stronger subgrade goes well with thin pavement layers. Conventionally, many stabilizers and techniques are available in the industry to tackle this problem. The present study is aimed at using an alternate and comparatively economical method. An attempt is made to use the concept of ground improvement technique for stabilizing the weak soil subgrade by inserting nails that are truncated cones and validating the results through CBR test. No fines concrete nails are inserted into the subgrade soil at various depth. The diameter and height of the no fines concrete nails is varied to get three different sized nails. The method is aimed at effective application for village roads carrying low traffic.
\end{abstract}

Keywords-Clayey soil, Subgrade, California Bearing Ratio(CBR), no fines concrete nail.

\section{I.INTRODUCTION}

In India, road connectivity is aimed at connecting even the remote villages. Schemes like Pradhan Mantri Gram Sadak Yojana (PMGSY) is initiated towards achieving the same. In case of poor subgrade condition, road construction on weak soil proves very costly. In many parts of India and Northern Karnataka, there is abundant presence of weak soil. Road construction on such would result in problems with construction, performance and maintenance in due course of time. Many of the conventional methods available for treatment of such weak subgrade soil are not economical and also not feasible considering the amount of investment towards low density traffic.

The aim of the present study is to strengthen the existing weak soil, which is clayey in nature, using no fine concrete nails. No-fines concrete is a form of light weight porous concrete, obtained by eliminating the sand from the normal concrete mix. The advantages of this type of concrete is having lower density, lower cost due to lower cement content, lower thermal conductivity, relatively low drying shrinkage, no segregation and capillary movement of water, better insulating characteristics than conventional concrete because of the presence of large voids. CBR test is conducted to validate the use of no fines concrete nails towards improvement of weak subgrade soil.

\section{OBJECTIVE OF THE STUDY}

- Improvement in the CBR value of the subgrade soil through insertion of no fines concrete nails.

- To study the effect of different sized no fines concrete nails on the improvement in subgrade strength.

- To determine the effect of nail depth on the subgrade strength.

\section{LITERATURE STUDIES}

A survey of the literature on the improvement in the performance of weak soils is presented in this chapter. As there are a multiple of methods in use, only few representatives are highlighted.

$\mathrm{T}$ Abadjieva and P Sephiri conducted investigation on nofines concrete and found out that the density and strength properties of the no-fines concrete are lower than that of normal concrete, but can be sufficient enough for structural use. They found that for practical purposes mix, the aggregate/cement ratio of $6: 1$ and $7: 1$ were recommended. They suggested that mixtures could be used for cast in-situ walls in low-rise structure, low cost housing (later plastered externally for reducing air and water permeability), drainage layers and paving after more extensive research.

An innovative soil nail installation method was developed, by Y.M. Cheng, S.K. Au, A.M. Pearson \& N. Li, 2003, for the Airport link in Australia, which combined the applications of fracture grouting techniques and composite Glass fiber reinforced polymer(GFRP) soil nails to stabilize the ground soil as well as compensate for the settlement of ground. 
Extensive laboratory and in-situ tests were carried out to verify the mass soil properties methods and the

performance of the geo-nail system for the local and global stabilization of the soft ground.

R.Santosh and V.Dinesh, 2015, choose admixtures that helped in stabilization of black cotton soil. The use of yard waste and geonails in combination proved to be a good solution for increasing the strength of the soil and that too in a rapid manner. Geonails being good stabilizing agents, are not effective on clays due to poor bonding and softness of clay. Therefore, yard waste was used as a catalyst to make the soil hard enough for intrusion by geonails, which would then impart high strength in quick time. work involved the combined use of yard waste and geo nails as soil stabilization agents and also the experiences gained through an experimental study at an agricultural field in outskirts of Coimbatore. From the study, it was concluded that the combination of geonails with yard waste helped in stabilizing the black cotton soil.

\section{MATERIALS AND METHODOLOGY}

For the present work, the clayey soil was taken near the Sondekoppa lake of Bengaluru district, Karnataka at a depth of 1.5 meter from the natural ground level. The obtained soil was moist and they are in the form of lumps. At first the soil is kept for surface dry for two days and the soil is break down into powdered and sieved with suitable sieve for further experimental purpose.

No fines concrete is a mixture of cement, water, and a single sized coarse aggregate these are combined to produce a porous structural material. It is referred by different names like zerofines concrete, pervious concrete and porous concrete.

In this study 53 grade cement and coarse aggregate passing $12.5 \mathrm{~mm}$ IS sieve and retained on $10 \mathrm{~mm}$ IS sieve is used. The cement to aggregate ratio used is 1:6. The basic tests on aggregate is carried out which includes specific gravity, flakiness, elongation and angularity number. The basic tests on cement like specific gravity, consistency, initial setting time and also compression strength of no fines concrete is to conducted.

Table 1. represent the dimension of the no fines concrete-nails used in the present study.

Table 1. Dimensions of the No fines concrete nails

\begin{tabular}{|c|c|c|c|}
\hline $\begin{array}{c}\text { Cone } \\
\text { no. }\end{array}$ & $\begin{array}{c}\text { Top diameter, } \\
\mathrm{cm}\end{array}$ & $\begin{array}{c}\text { Bottom diameter, } \\
\mathrm{cm}\end{array}$ & Height, cm \\
\hline 1 & 5 & 2.5 & 2.16 \\
\hline 2 & 7.5 & 2.5 & 4.33 \\
\hline 3 & 10 & 2.5 & 6.49 \\
\hline
\end{tabular}

The no fines concrete nails are tapered to an angle of $60^{\circ}$ in consideration of dynamic cone penetration test specifications. The nails are inserted in the CBR mould at $2.5 \mathrm{~cm}$ from the top of CBR mould for all three different sizes and to find the CBR values of normal soil and treated with different soil and to compare the strength of different sized cones at different depth and to derive a relation between the test was conducted.
Figure 1 and figure 2 shows the casting and casted no fines concrete nails for the experimental study.

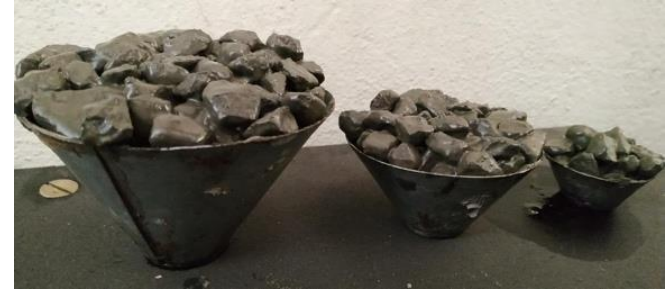

Fig 1. Casting of No fines concrete of three different dimensions

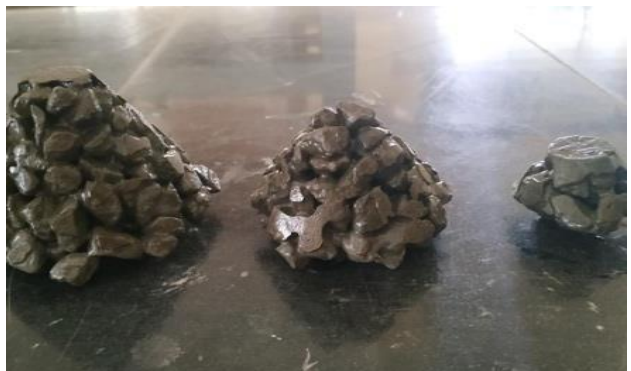

Fig 2. Casted No fines concrete nails of three different dimensions

\section{EXPERIMENTAL STUDY}

The tests are conducted as per Indian Standard code practice. The basic properties of the clayey soil, cement, aggregates and no fines concrete are provided in the tables below. The tests pertaining to soil are carried out for specific gravity, liquid limit, plastic limit, shrinkage limit, plasticity index, unconfined compression strength, compaction, grain size analysis and CBR values. These tests are important to understand the properties of the existing weak subgrade soil. Specific gravity, water absorption, flakiness index, elongation index, combined index and angularity number of the aggregates is determined. Tests conducted on cement include specific gravity, normal consistency, fineness and setting time. Compressive strength test is carried out on fines concrete cube in line with the regular concrete cube testing as per IS standard and the results are mentioned in the table.

Table 2. represents the test results of soil sample. Table 3 . and table 4. gives the results of test conducted on aggregate and cement respectively.

Table 5. Shows the compressive strength value of no fines concrete cube.

\begin{tabular}{|c|c|}
\hline Test & Result \\
\hline Specific Gravity & 2.467 \\
\hline Liquid limit & $63 \%$ \\
\hline Plastic limit & $28.5 \%$ \\
\hline Shrinkage limit & $22.07 \%$ \\
\hline Plasticity index & $34.83 \%$ \\
\hline $\begin{array}{ll}\text { Unconfined } & \text { compression } \\
\text { strength } & \end{array}$ & $\begin{array}{l}\mathrm{C}=0.18 \mathrm{~N} / \mathrm{mm}^{2} \\
\emptyset=42^{\circ}\end{array}$ \\
\hline Compaction test & $\begin{array}{l}\text { Maximum dry density } \\
=14.1 \mathrm{gm} / \mathrm{cc} \text { Optimum } \\
\text { moisture content = } \\
16.4 \%\end{array}$ \\
\hline
\end{tabular}




\begin{tabular}{|l|l|}
\hline Sieve analysis & $\mathrm{C}_{\mathrm{u}}=8.88$ and $\mathrm{C}_{\mathrm{c}}=1.9$ \\
\hline Hydrometer analysis & $45 \%$ \\
\hline $\begin{array}{l}\text { California Bearing ratio - } \\
\text { unsoaked and soaked } \\
\text { conditions }\end{array}$ & $\begin{array}{l}4.22 \% \text { and } 0.22 \% \\
\text { respectively }\end{array}$ \\
\hline
\end{tabular}

Table 3. Test on Aggregates

\begin{tabular}{|c|c|}
\hline Test & Result \\
\hline Specific gravity & 2.70 \\
\hline Water Absorption & $0.2 \%$ \\
\hline Flakiness Index & $6.5 \%$ \\
\hline Elongation Index & $18.69 \%$ \\
\hline Combined Index & $25.19 \%$ \\
\hline Angularity number & 8 \\
\hline
\end{tabular}

Table 4. Test on Cement

\begin{tabular}{|c|c|}
\multicolumn{2}{c}{ Table 4. Test on Cement } \\
\hline Test & Result \\
\hline Specific gravity & 3.15 \\
\hline Normal Consistency & $33 \%$ \\
\hline Fineness & $96 \%$ \\
\hline Initial setting time & $45 \mathrm{~min}$ \\
\hline Final setting time & $570 \mathrm{~min}$ \\
\hline
\end{tabular}

Table 5. Compressive strength test on no fines concrete

\begin{tabular}{|l|l|}
\hline Compressive strength test & \multicolumn{1}{|c|}{ Result } \\
\hline 7 days strength & $11 \mathrm{~N} / \mathrm{mm}^{2}$ \\
\hline 14 days strength & $15 \mathrm{~N} / \mathrm{mm}^{2}$ \\
\hline 28 days strength & $19.5 \mathrm{~N} / \mathrm{mm}^{2}$ \\
\hline
\end{tabular}

The casted no fines concrete nails are inserted in the CBR mould manually and tested for unsoaked and 4 days soaked conditions.

As per IRC:37-2001, the CBR values are calculated.

Table 6. represents the CBR test values of weak subgrade soil inserted with different size no fines concrete nails.

Table 6. CBR values of no fines concrete nails

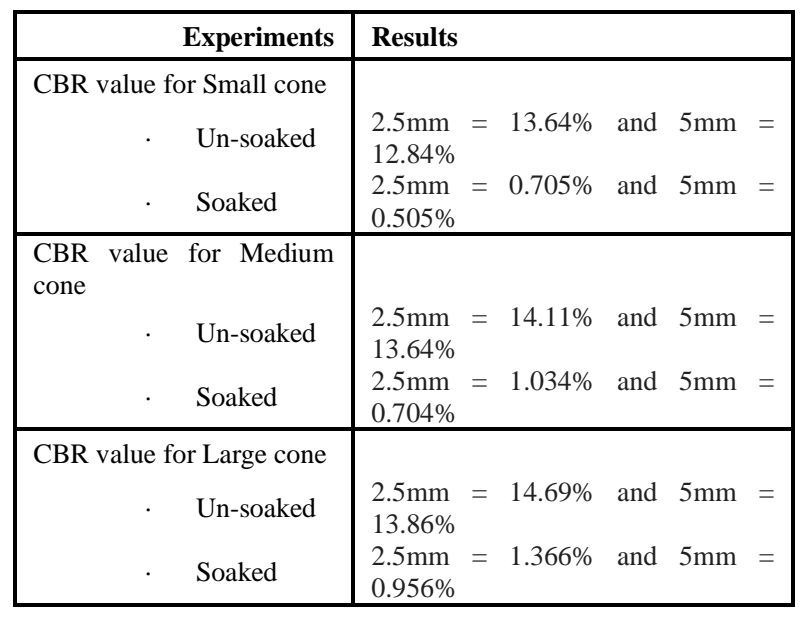

Table 7 and Table 8 show the percentage increase in the CBR values as compared to the CBR value of normal weak subgrade soil sample.
Table 7. Percentage increase of CBR values for unsoaked conditions

\begin{tabular}{|l|l|}
\hline Soil sample with & \% increase in CBR value \\
\hline Small cone & 69.62 \\
\hline Medium Cone & 71.4 \\
\hline Large cone & 71.86 \\
\hline
\end{tabular}

Table 8. Percentage increase of CBR values for soaked conditions

\begin{tabular}{|l|l|}
\hline Soil sample with & \% increase in CBR value \\
\hline Small cone & 68.65 \\
\hline Medium Cone & 77.9 \\
\hline Large cone & 83.82 \\
\hline
\end{tabular}

Figure. 3 and Fig. 4 graphically represent the improvement in CBR values compared to that of the weak subgrade sample considered for the study.

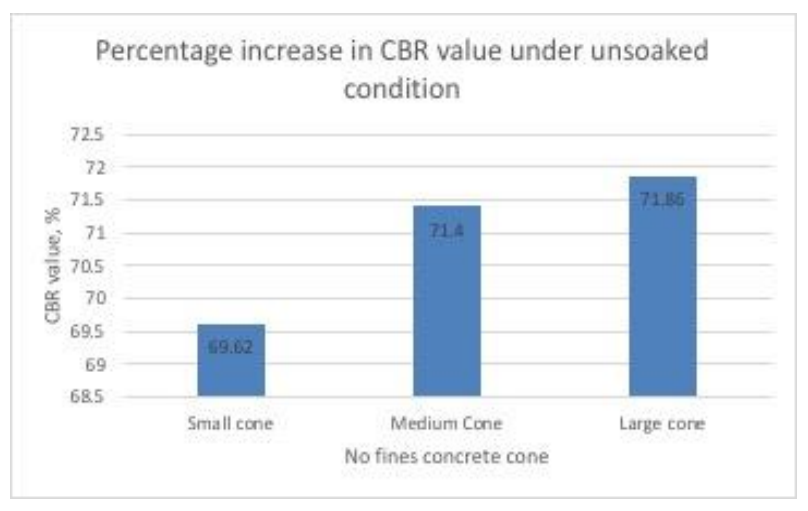

Fig 3. Percentage increase in CBR value under unsoaked condition

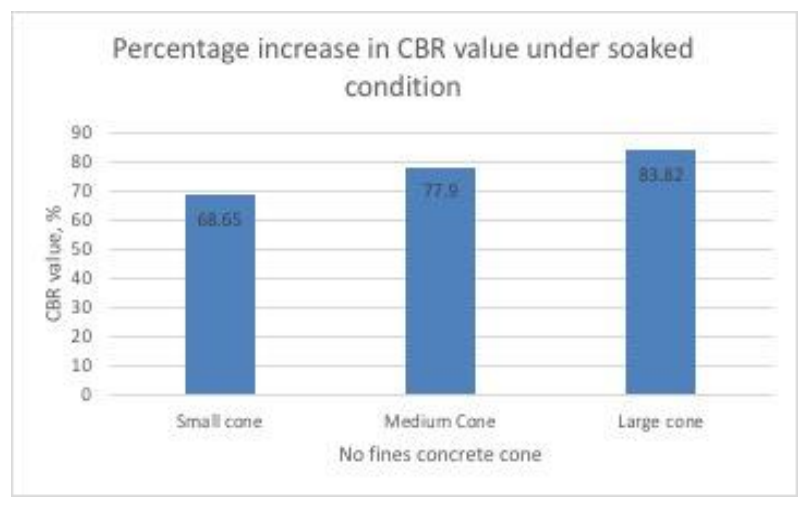

Fig 4. Percentage increase in CBR value under soaked condition

\section{CONCLUSION}

- $\quad$ All figures and tables shall be numbered sequentially and cited with the discussion in the main body of the paper.

- No fine concrete nails increase strength of subgrade and reduces the thickness of pavement.

- Driving of no fines concrete nails into soil improves the CBR value and the load carrying capacity of weak soil depending on the size and number of nails. 
- The CBR value gradually increases on insertion of nails with increase in its size.

\section{SCOPE FOR FURTHER STUDY}

The magnitude of increase in the CBR value of soil in case of all the three size nails used is very marginal. Further study is needed to optimize the size of the nail so as to achieve good CBR value, thereby decreasing the overall pavement thickness and making it economically viable.

\section{VIII.REFERENCES}

[1] Amu. O.O., Fajobi. A.B., and Oke. B.O., (2005) "Effect of Egg Shell Powder on the Stabilising Potential of Lime on an Expansive Clay Soil" Journal of Applied Sciences, 5 (8): pp 1474 -1478.

[2] Bhyravavajhala (2003).," Experimental and theoretical study of pileanchors on weak soil'ICGGE-2004 IIT Bombay.

[3] JiJO JAMES and P. Kasinatha pandian (2013), "Soil Stabilization using Natural Materials”, ISSN 0974-5904, Vol-6, No.1, Feb 2013

[4] Ranjitha J and Rajasekhara M R (2018), "soil stabilization by using no fines concreten nails", IJRET, Vol-7, Issue-02, Feb 2018

[5] Ravindra Budania, Dr R P Arora, (2016), "Soil Nailing for Slope Stablization", IJESC, vol-6, Issue No12, Dec 2016

[6] R Santhosh, V Dinesh (2015),"Soil stabilisation for clayey soils using geonails and yard waste", IJEREST, Vol-2, Issue-4, 4 April 2015

[7] Sharma P (2015), "Theoretical analysis and soil nailing: design, performed and future aspects, IJERGS

[8] Vikash Kumar Gautam, Devash Jaysawal (2017), "Soil stabilization by using bitumenous material”, IRJET, Vol-4, Issue-11,Nov 2017

[9] IS 2720(part 2)-1973 „Determination of water content ${ }^{\text {e }}$

[10] IS 2720 (part 3/sec 1)-1980, , Determination of specific gravity ${ }^{\text {ee }}$

[11] IS 2720 (part 5)-1985, ,Determination of liquid and plastic limit.

[12] IS 2720 (part 7)1980, Determination of water content-Dry density relation using Light compaction

[13] "Highway engineering"- S K Kanna, C E G Justo, A Veeraragavan.

[14] "Basic and applied soil mechanics",Gopal ranjan and A.S.R Rao, second edition 2000, New age International (P) Ltd publisher Delhi. 